Perbal: Jurnal Pertanian Berkelanjutan

Volume 10 No.1 Februari 2022

ISSN 2302-6944,e-ISSN2581-1649

\title{
IDENTIFIKASI MORFOLOGI DAN EKOLOGI PADA TUMBUHAN LIAR YANG BERPOTENSI SEBAGAI SUMBER VITAMIN C
}

\author{
Identification of Morphology and Ecology in Potential Wild Plants as Sources of Vitamin C
}

\author{
Rahmi Azizah Mudaffar
}

Program Studi Agroteknologi, Fakultas Pertanian, Universitas Andi Djemma Palopo

cicaami@gmail.com

\begin{abstract}
ABSTRAK
Sebagian masyarakat menganggap tumbuhan liar adalah tumbuhan pengganggu atau gulma padahal beberapa tumbuhan liar memiliki manfaat untuk kesehatan dan kebugaran tubuh, utamanya tumbuhan liar yang berpotensi mengandung vitamin C. Penelitian ini bertujuan untuk mengetahui identifikasi morfologi dan ekologi tumbuhan liar yang ada di Kabupaten Luwu yang berpotensi sebagai sumber vitamin C. Penelitian ini dilaksanakan di tiga desa dengan tiga lokasi tumbuh yang berbeda yaitu di dataran tinggi, dataran sedang dan ditaran rendah. Tiga desa yang mewakili yaitu desa Latimijong, Tetekang dan Bua. Metode yang digunakan adalah metode survey dan wawancara. Hasil penelitian ini menunjukkan bahwa karakter morfologi dan ekologi tumbuhan di dataran rendah cenderung lebih memenuhi syarat-syarat tanaman yang berpotensi sebagai sumber vitamin $C$ terutama dari warna dan kemasamannya $(\mathrm{pH})$. Terdapat enam jenis tumbuhan liar yaitu senggani, ciplukan, kecombrang, dengen, buni, dan rambusa pada tiga lokasi berbeda yang memiliki potensi sebagai sumber vitamin $\mathrm{C}$ dan telah dimanfaatkan oleh masyarakat setempat.
\end{abstract}

Kata kunci : ekologi, morfologi, tumbuhan liar, vitamin C

\section{ABSTRACT}

Some people think that wild plants are invasive plant or weeds even though some wild plants have benefits for health and body fitness, especially wild plants that have the potential to contain vitamin $C$. This study aimed to identify the morphology and ecology of wild plants in Luwu Regency that have the potential as sources of vitamin C. This research was carried out in three villages with three different growing locations, namely in the highlands, mediumlands and lowlands. The three representative villages are Latimijong, Tetekang and Bua villages. The method used is survey and interview methods. The results of this study indicate that the morphological and ecological characters of plants in the lowlands tend to meet the requirements of plants that are potential sources of vitamin $C$, especially from their color and acidity $(\mathrm{pH})$. There are six types of wild plants, namely senggani, ciplukan, kecombrang, dengen, buni, and rambusa in three different locations that have potential as sources of vitamin $C$ and have been used by local communities.

Keywords: ecology, morphology, vitamin C, wild plants

\section{PENDAHULUAN}

Ciri-ciri tanaman yang mengandung vitamin $\mathrm{C}$ antara lain kandungan airnya tinggi sehingga daging buahnya berair, secara kimiawi memiliki sifat asam, cenderung memiliki warna cerah seperti kuning, orange, dan hijau cerah, namun kadar asamnya tergantung dari tingkat $\mathrm{pH}$ pada tanaman, dengan tingkat keasaman atau $\mathrm{pH}$ antara 2-4, Semakin besar kandungan asamnya justru semakin rendah nilai pHnya, sebaliknya semakin kecil kandungan asamnya justru semakin tinggi nilai pHnya (Guyton, 2007).

Potensi tanaman yang mengandung vitamin $\mathrm{C}$ juga terkandung pada beberapa 
tanaman liar antara lain ; dengen, belimbing bajo, kecombrang, ciplukan (lappo-lappo), senggani, bunne (buni), dan rambusa. Buah dengen mengandung $84 \%$ sari vitamin $\mathrm{C}$ (Crashed, 2009), belimbing bajo mengandung $75 \%$ dari asupan vitamin C (Mayasari, 2016), kecombrang atau di Sulawesi Selatan disebut kecombrang memiliki kandungan vitamin $\mathrm{C}$ yang lebih tinggi dibandingkan kandungan vitamin C pada buah papaya (Shafira dkk, 2018), pada buah ciplukan didapatkan hasil rata-rata vitamin $\mathrm{C}$ yaitu pada buah ciplukan yang mentah didapatkan hasil 8,8\% sedangkan pada buah ciplukan yang matang didapatkan hasil 22,88\% (Pratiwi, 2018). Senggani mengandung vitamin $\mathrm{C}$ sebesar $\pm 1,73 \mathrm{ppm}$ (Kesuma, dkk, 2016), untuk buah rambusa mengandung $30 \mathrm{mg}$ dari $100 \mathrm{~g}$ bahan, bunne (buni) mengandung vitamin sebesar 52,23\% lebih tinggi dibandingkan belimbing bajo yang setengah matang (Garjito, 2013).

Belum banyak masyarakat yang mengetahui bahwa beberapa tanaman liar memiliki manfaat untuk kesehatan dan kebugaran tubuh, tanaman hias, pewarna alami, biogas, dan beberapa potensi lainnya. Perlu adanya identifikasi baik itu secara morfologi dan ekologi seingga dengan melihat potensi-potensi yang ada, dapat dijadikan suatu peluang untuk dikembangkan baik itu melalui pembudidayaan maupun dikomersialkan.

\section{Tujuan dan Kegunaan Penelitian}

Penelitian ini bertujuan untuk melakukan identifikasi morfologi dan ekologi tumbuhan yang ada di Kabupaten Luwu yang berpotensi sebagai sumber vitamin $\mathrm{C}$.

\section{METODE PENELITIAN}

\section{Waktu dan Tempat}

Penelitian ini dilaksanakan dalam bentuk survey di lapangan pada Kabupaten Luwu, Kecamatan Bajo Barat, di Desa Latimojong, Desa Tetekang dan Desa Bua yang mewakili dataran tinggi, dataran sedang, dan dataran rendah pada bulan Oktober sampai November 2021.

\section{Alat dan Bahan}

Alat-alat yang digunakan yaitu, timbangan analitik, soil tester, gunting, pisau/cetter, plastik, amplop, kantongan kresek, spidol, label, saringan, blender, dan kamera. Bahan-bahan yang digunakan yaitu, air, aquades, dan $\mathrm{pH}$ meter yang akan digunakan di gunakan masing-masing tiga lokasi yang berbeda-beda.

\section{Metode Penelitian}

Metode penelitian ini dilakukan dengan cara survey dan wawancara. Pemilihan sampel dilakukan dengan alasan tertentu (purposif sampling) yaitu dataran tinggi berkisar 1400$2000 \mathrm{~m}$ dpl, dataran sedang berkisar 700-1400 
m dpl, dan dataran rendah 0-700 $\mathrm{m}$ dpl yang menggunakan metode eksplorasi melalui observasi, dengan penyajian data dilakukan secara deskriptif, kuantitatif, dan kualitatif. Adapun cara kerja penelitian ini yaitu, penelitian lokasi sampling, pengoleksian sampel, karakteristik determinasi, identifikasi, dan visualisasi sampel, serta analisis data untuk pengelompokkan. Adapun yang akan diteliti yaitu identifikasi morfologi (daun, batang, akar, bunga, buah, dan biji) dan identifikasi ekologi (habitat). Identifikasi tersebut akan berfokus pada tanaman liar yang memang sudah dimanfaatkan oleh masyarakat sekitar dan tanaman liar yang menurut pustaka/literatur memiliki potensi akan tetapi masyarakat belum mengetahui dan belum memanfaatkannya.

\section{Metode Pelaksanaan}

\section{Penentuan Lokasi Sampel}

Secara umum, Kabupaten Luwu berada pada ketinggian berkisar antara 0- $2000 \mathrm{mdpl}$. Maka untuk penentuan tinggi tempat dibagi tiga yaitu dataran tinggi berkisar 1400-2000 mdpl yang berada di Desa Latimojong, dataran sedang berkisar 700-1400 yang berada di Desa Tetekang, dan dataran rendah 0-700 mdpl yang berada di Desa Bua.

\section{Pemilihan Jenis Tanaman Sampel}

Penentuan pemilihan jenis tanaman sampel adalah adanya beberapa tanda atau indikator suatu tanaman yang mengandung vitamin $\mathrm{C}$ yaitu tanaman berwarna kuning, orange, dan hijau cerah sedangkan pada tingkat keasaman pada buah itu berbeda-beda tergantung dari tempat habitat tumbuhanya yang dipengaruhi oleh tinggi rendahnya suatu tempat. Rasa asam yang ada juga dapat disebabkan oleh adanya vitamin $\mathrm{C}$.

\section{Parameter yang Diamati dan Diukur :}

\section{Identifikasi Tumbuhan}

Pengamatan ini dilakukan dengan cara survey ditempat pengambilan sampel tentang nama lokal, nama Indonesia, dan nama ilmiah.

\section{Morfologi Tumbuhan}

Pengamatan ini dilakukan dengan mengamati bagian-bagian dan bentuk-bentuk dari batang (bentuk batang, percabangan pada batang, arah tumbuh batang, dan warna batang), bentuk daun (bentuk ujung daun, warna daun, permukaan daun), bentuk bunga (warna bunga, letak bunga, bentuk bunga, dan jumlah bunga), bentuk buah (penggolongan buah semu, penggolongan buah sungguh/buah sejati, buah sejati ganda, buah sejati majemuk), dan bentuk biji pada tanaman (bentuk biji dan warna biji).

\section{Habitat/Ekologi Tumbuhan}

Pengamatan ini dilakukan dengan cara pengumpulan data dari tempat pengambilan sampel yang berupa ketinggian tempat/attitude, kondisi tanah (basah dan 
Perbal: Jurnal Pertanian Berkelanjutan

Fakultas Pertanian Universitas Cokroaminoto Palopo

kering), tekstur tanah (berpasir, liat lempung, tanaman yang berpotensi sebagai sumber dll), dan tempat tumbuh (di tempat terbuka dan vitamin $\mathrm{C}$ yang berada di dataran tinggi, dibawah naungan).

\section{Analisis Data}

Hasil penelitian akan dianalisis dengan mengunakan metode survey sehingga kita dataran sedang, dan dataran rendah, sehingga dapat terlihat jelas perbedaan tanaman pada daerah yang menjadi tempat pengambilan dapat membedakan morfologi dan habitat sampel.

\section{HASIL DAN PEMBAHASAN}

\section{HASIL}

\section{Identifikasi Tumbuhan}

Tabel 1. Identifikasi nama tumbuhan yang berpotensi sebagai sumber vitamin $\mathrm{C}$ di Kabupaten Luwu

\begin{tabular}{|c|c|c|c|c|c|c|c|c|c|}
\hline \multirow{2}{*}{ Nama } & \multicolumn{3}{|c|}{ Dataran Tinggi } & \multicolumn{3}{|c|}{ Dataran Sedang } & \multicolumn{3}{|c|}{ Dataran Rendah } \\
\hline & N. Lo & N. In & N. Im & N. Lo & N. In & N. Im & N. Lo & N. In & N. Im \\
\hline Senggani & $\begin{array}{l}\text { Latta- } \\
\text { latta }\end{array}$ & Senggani & $\begin{array}{l}\text { Melosto } \\
\text { ma }\end{array}$ & $\begin{array}{l}\text { Latta- } \\
\text { latta }\end{array}$ & $\begin{array}{l}\text { Sengga } \\
\text { ni }\end{array}$ & $\begin{array}{l}\text { Melosto } \\
\text { ma }\end{array}$ & $\begin{array}{l}\text { Latta- } \\
\text { latta }\end{array}$ & $\begin{array}{l}\text { Sengga } \\
\text { ni }\end{array}$ & Melostoma \\
\hline Ciplukan & - & Ciplukan & $\begin{array}{l}\text { Physialis } \\
\text { angulate }\end{array}$ & $\begin{array}{l}\text { Lappo- } \\
\text { lappo }\end{array}$ & $\begin{array}{l}\text { Ciplu } \\
\text { kan }\end{array}$ & $\begin{array}{l}\text { Physialis } \\
\text { angulate }\end{array}$ & $\begin{array}{l}\text { Lappo- } \\
\text { lappo }\end{array}$ & $\begin{array}{l}\text { Ciplu } \\
\text { kan }\end{array}$ & $\begin{array}{l}\text { Physialis } \\
\text { angulate }\end{array}$ \\
\hline Patikala & $\begin{array}{l}\text { Batikal } \\
\text { a }\end{array}$ & $\begin{array}{l}\text { Kecomb } \\
\text { rang }\end{array}$ & $\begin{array}{l}\text { Etingera } \\
\text { ealatior }\end{array}$ & $\begin{array}{l}\text { Batika } \\
\text { la }\end{array}$ & $\begin{array}{l}\text { Kecom } \\
\text { brang }\end{array}$ & $\begin{array}{l}\text { Etingera } \\
\text { ealatior }\end{array}$ & $\begin{array}{l}\text { Batika } \\
\text { la }\end{array}$ & $\begin{array}{l}\text { Kecom } \\
\text { brang }\end{array}$ & $\begin{array}{l}\text { Etingera } \\
\text { ealatior }\end{array}$ \\
\hline Dengen & - & Dengen & $\begin{array}{l}\text { Dillenia } \\
\text { Serreta }\end{array}$ & Dengen & Dengen & $\begin{array}{l}\text { Dillenia } \\
\text { Serreta }\end{array}$ & Dengen & Dengen & $\begin{array}{l}\text { Dillenia } \\
\text { Serreta }\end{array}$ \\
\hline Buni & Bunne & Buni & $\begin{array}{l}\text { Antidesm } \\
\text { a bunius }\end{array}$ & Bunne & Buni & $\begin{array}{l}\text { Antidesm } \\
\text { a bunius }\end{array}$ & Bunne & Buni & $\begin{array}{l}\text { Antidesma } \\
\text { bunius }\end{array}$ \\
\hline Rambusa & Bibbi & Rambusa & $\begin{array}{l}\text { Passiflor } \\
\text { a foetida }\end{array}$ & Bibbi & $\begin{array}{l}\text { Rambu } \\
\text { sa }\end{array}$ & $\begin{array}{l}\text { Passiflor } \\
\text { a foetida }\end{array}$ & Bibbi & $\begin{array}{l}\text { Rambu } \\
\text { sa }\end{array}$ & $\begin{array}{l}\text { Passiflora } \\
\text { foetida }\end{array}$ \\
\hline
\end{tabular}

Sumber : Data Primer (2021)

Keterangan: N.Lo = Nama Lokal $;$ N.In = Nama Indonesia $;$ N.Im = Nama Ilmiah.

Pengamatan pada bagian jenis masyarakat hanya memanfaatkan tumbuhan tumbuhan pada tiga lokasi menunjukkan liar seperti senggani, ciplukan, kecombrang, adanya perbedaan, tidak semuanya jenis dengen, buni, dan rambusa, sedangkan di tumbuhan yang ada di dataran rendah ada pada daratan rendah masyarakat lebih banyak dataran tinggi dan dataran sedang. Di dataran mengenal tumbuhan liar seperti senggani, tinggi masyarakat hanya memanfaatkan ciplukan, kecombrang, dengen, buni, dan tumbuhan liar seperti senggani, kecombrang, rambusa. buni, dan rambusa, di dataran sedang 


\section{Morfologi Tumbuhan}

Tabel 2. Morfologi umum dari tumbuhan senggani yang berpotensi sebagai sumber vitamin C

\begin{tabular}{|c|c|c|c|c|c|}
\hline \multirow{2}{*}{$\begin{array}{l}\text { Nama } \\
\text { tumbuhan }\end{array}$} & \multicolumn{5}{|c|}{ Morfologi tumbuhan } \\
\hline & Akar & Batang & Daun & Bunga & $\begin{array}{l}\text { Buah/ } \\
\text { Biji }\end{array}$ \\
\hline Senggani & $\begin{array}{l}\text { Tunggang } \\
\text { dan } \\
\text { berwarna } \\
\text { coklat. } \\
\text { L }\end{array}$ & $\begin{array}{l}\text { Berkayu, } \\
\text { bulat, } \\
\text { berbulu } \\
\text { rapat atau } \\
\text { bersisik, } \\
\text { percabangan } \\
\text { simpodial, } \\
\text { coklat. } \\
\text { som }\end{array}$ & $\begin{array}{l}\text { Tunggal, bulat } \\
\text { telur, panjang } \\
2-20 \mathrm{~cm} \text {, lebar } \\
1-8 \mathrm{~cm} \text {, } \\
\text { berhadapan, } \\
\text { ujung dan } \\
\text { pangkal } \\
\text { runcing, tepi } \\
\text { rata, berbulu, } \\
\text { dan hijau. }\end{array}$ & $\begin{array}{l}\text { Majemuk, kelopak } \\
\text { berlekatan, berbulu, bagian } \\
\text { ujung pendek dari pangkal, } \\
\text { ujung meruncing, daun } \\
\text { pelindung bersisik, ungu } \\
\text { kemerahan, benang sari, } \\
\text { merah muda, putik, kepala } \\
\text { putik berbintik hijau, bakal } \\
\text { buah, mahkota 5, bulat telur, } \\
\text { dan ungu. }\end{array}$ & $\begin{array}{l}\text { Bulat telur dan } \\
\text { berwarna } \\
\text { merah. } \\
\text { Biji: Kecil dan } \\
\text { berwarna } \\
\text { merah. }\end{array}$ \\
\hline
\end{tabular}

Sumber : Data Primer (2021)

Tabel 3. Morfologi umum dari tumbuhan ciplukan yang berpotensi sebagai sumber vitamin C

\begin{tabular}{|c|c|c|c|c|c|}
\hline \multirow{2}{*}{$\begin{array}{l}\text { Nama } \\
\text { tumbuhan }\end{array}$} & \multicolumn{5}{|c|}{ Morfologi tumbuhan } \\
\hline & Akar & Batang & Daun & Bunga & $\begin{array}{l}\text { Buah/ } \\
\text { Biji }\end{array}$ \\
\hline $\begin{array}{l}\text { Ciplukan } \\
\end{array}$ & $\begin{array}{l}\text { Akar tunggang, } \\
\text { bercabang, dan } \\
\text { berserabut } \\
\text { Berwarna } \\
\text { keputihan kotor } \\
\text { hingga } \\
\text { kecoklatan, } \\
\text { selain itu akar } \\
\text { tumbuhan ini } \\
\text { intensif yang } \\
\text { menyebar hanya } \\
\text { di permukaan } \\
\text { tanah. } \\
\end{array}$ & $\begin{array}{l}\text { Batang tegak, } \\
\text { lunak, } \\
\text { berbentuk } \\
\text { bulat, beralur } \\
\text { dan berwarna } \\
\text { kecoklatan. } \\
\text { Batang juga } \\
\text { berusuk, } \\
\text { bersegi lancip, } \\
\text { berongga, } \\
\text { bercabang } \\
\text { banyak dan } \\
\text { memiliki } \\
\text { kehijauan } \\
\text { mudah. } \\
\end{array}$ & $\begin{array}{l}\text { Daun tunggal, } \\
\text { bertangkai } \\
\text { banyak, letak di } \\
\text { bagian bawah, } \\
\text { daun berbentuk } \\
\text { bulat telur, dan } \\
\text { memanjang. } \\
\text { Pangkal daun } \\
\text { meruncing, } \\
\text { bagian tepi } \\
\text { merata, tangkai } \\
\text { daun berwarna } \\
\text { kehijauan muda } \\
\text { dan pertulangan } \\
\text { menyirip yang } \\
\text { berwarna } \\
\text { keputihan. }\end{array}$ & $\begin{array}{l}\text { Bunga tunggal, } \\
\text { muncul pada ketiak } \\
\text { daun, kelopak } \\
\text { bunga terbagi } 5 \text {, } \\
\text { dan taju bersudut } 3 \\
\text { serta meruncing. } \\
\text { Mahkota tumbuhan } \\
\text { ini berbentuk } \\
\text { lonceng berwarna } \\
\text { kecoklatan. Selain } \\
\text { itu, ada terdapat } \\
\text { bulu halas, dan } \\
\text { memiliki tangkai } \\
\text { benang sari } \\
\text { berwarna } \\
\text { kekuningan pucat } \\
\text { dan kepala benang } \\
\text { sari berwarna biru } \\
\text { muda. }\end{array}$ & $\begin{array}{l}\text { Buah berbentuk } \\
\text { bulat oval, berwarna } \\
\text { kehijauan muda } \\
\text { hingga kekuningan, } \\
\text { terbungkus dalam } \\
\text { kelopak } \\
\text { mengelumbung. } \\
\text { Selain itu, buah ini } \\
\text { memiliki biji-biji } \\
\text { halus didalamnya } \\
\text { berwarna keputihan } \\
\text { yang diselimuti } \\
\text { serat halus dan juga } \\
\text { buah ini memiliki } \\
\text { rasa manis. } \\
\text { Biji : Kecil } \\
\text { berwarna putih } \\
\text { berbentuk bulat } \\
\text { tipis. }\end{array}$ \\
\hline
\end{tabular}

Sumber : Data Primer (2021) 
Perbal: Jurnal Pertanian Berkelanjutan

Fakultas Pertanian Universitas Cokroaminoto Palopo

Tabel 4. Morfologi umum dari tumbuhan kecombrang yang berpotensi sebagai sumber vitamin C

Nama

\begin{tabular}{|c|c|c|c|c|c|}
\hline $\begin{array}{l}\text { Nama } \\
\text { tumbuhan }\end{array}$ & Akar & Batang & Daun & Bunga & $\begin{array}{l}\text { Buah/ } \\
\text { Biji }\end{array}$ \\
\hline Kecombrang & $\begin{array}{l}\text { Bentukn } \\
\text { ya mirip } \\
\text { dengan } \\
\text { tanaman } \\
\text { lengkuas } \\
\text { dan jahe. } \\
\text { KKa }\end{array}$ & $\begin{array}{l}\text { Batang semu } \\
\text { bulat gilig, } \\
\text { membesar } \\
\text { dipangkal nya, } \\
\text { tumbuh tegak dan } \\
\text { banyak, berdekat- } \\
\text { dekatan, } \\
\text { membentuk } \\
\text { rumpun jarang, } \\
\text { keluar dari } \\
\text { rimpang yang } \\
\text { menjalar di bawah } \\
\text { tanah. Rimpang } \\
\text { nya tebal, } \\
\text { berwarna krem, } \\
\text { kemerah-jambuan } \\
\text { ketika masih } \\
\text { muda. } \\
\quad \text { HHH }\end{array}$ & $\begin{array}{l}\text { Daun } 15=30 \text { helai } \\
\text { tersusun dalam dua } \\
\text { baris, berseling, di } \\
\text { batang semu, } \\
\text { helaian daun jorong } \\
\text { lonjong, dengan } \\
\text { pangkal membulat } \\
\text { atau bentuk } \\
\text { jantung, tepi } \\
\text { bergelombang, dan } \\
\text { ujung meruncing } \\
\text { pendek, gundul } \\
\text { namun dengan } \\
\text { bintik-bintik halus } \\
\text { dan rapat, hijau } \\
\text { mengkilap, sering } \\
\text { dengan sisi bawah } \\
\text { yang keunguan } \\
\text { ketika muda. }\end{array}$ & $\begin{array}{l}\text { Dalam karangan } \\
\text { berbentuk gasing, } \\
\text { bertangkai panjang } \\
\text { dengan daun } \\
\text { pelindung bentuk } \\
\text { jorong, merah jambu } \\
\text { hingga merah terang, } \\
\text { berdaging, } \\
\text { melengkung } \\
\text { membalik jika mekar. } \\
\text { Kelopak bentuk } \\
\text { tabung, bertaju 3, } \\
\text { terbelah. Mahkota } \\
\text { bentuk tabung, merah } \\
\text { jambu, hingga } 4 \text { cm. } \\
\text { dan labellum } \\
\text { berwarna merah } \\
\text { terang dengan tepian } \\
\text { putih atau kuning }\end{array}$ & $\begin{array}{l}\text { Buah berjejalan } \\
\text { dalam bongkol } \\
\text { hamper bulat, } \\
\text { berambut halus } \\
\text { pendek di } \\
\text { luarnya, hijau dan } \\
\text { menjadi merah } \\
\text { ketika masak. } \\
\text { Biji : Berbiji } \\
\text { banyak, coklat } \\
\text { kehitaman, } \\
\text { diselubungi salut } \\
\text { biji putih bening } \\
\text { atau kemerahan } \\
\text { yang berasa asam. } \\
\end{array}$ \\
\hline
\end{tabular}

Sumber : Data Primer (2021)

Tabel 5. Morfologi umum dari tumbuhan dengen yang berpotensi sebagai sumber vitamin $\mathrm{C}$

\begin{tabular}{|c|c|c|c|c|c|}
\hline \multirow{2}{*}{$\begin{array}{l}\text { Nama } \\
\text { tumbuhan }\end{array}$} & \multicolumn{5}{|c|}{ Morfologi tumbuhan } \\
\hline & Akar & Batang & Daun & Bunga & $\begin{array}{l}\text { Buah/ } \\
\text { Biji }\end{array}$ \\
\hline Dengen & $\begin{array}{l}\text { Tunggang, } \\
\text { berkayu } \\
\text { berwarna } \\
\text { kecoklatan. }\end{array}$ & $\begin{array}{l}\text { Tumbuh hingga mencapai } \\
15-30 \mathrm{~m} \text {, batang bebas } \\
\text { cabang hingga } 17 \mathrm{~m} \text {, } \\
\text { memiliki garis tengah } \\
\text { batang sampai } 1 \mathrm{~m} \text {, batang } \\
\text { biasanya coklat atau abu- } \\
\text { abu licin. Batang utama } \\
\text { bercabang banyak } \\
\text { sehingga membentuk tajuk } \\
\text { yang rindang, sering kali } \\
\text { berbanir. }\end{array}$ & $\begin{array}{l}\text { Daun } \\
\text { merupakan } \\
\text { daun tunggal, } \\
\text { berwarna hijau } \\
\text { gelap, dan } \\
\text { duduk } \\
\text { berselang- } \\
\text { seling. }\end{array}$ & $\begin{array}{l}\text { Bunga berukurang } \\
\text { sedang, tersusun } \\
\text { dalam tandan, } \\
\text { berwarna mula- } \\
\text { mula hijau terang } \\
\text { dan menjadi putih } \\
\text { pada saat mekar. }\end{array}$ & $\begin{array}{l}\text { Basa } \\
\text { berdaging } \\
\text { berbentuk } \\
\text { agak bulat. } \\
\text { Biji : Kecil } \\
\text { berbentuk } \\
\text { bulat tipis. }\end{array}$ \\
\hline
\end{tabular}

Sumber : Data Primer (2021) 
Tabel 6. Morfologi umum dari tumbuhan buni yang berpotensi sebagai sumber vitamin C

\begin{tabular}{|c|c|c|c|c|c|}
\hline \multirow{2}{*}{$\begin{array}{l}\text { Nama } \\
\text { tumbuha } \\
\mathrm{n}\end{array}$} & \multicolumn{5}{|c|}{ Morfologi tumbuhan } \\
\hline & Akar & Batang & Daun & Bunga & $\begin{array}{l}\text { Buah/ } \\
\text { Biji }\end{array}$ \\
\hline 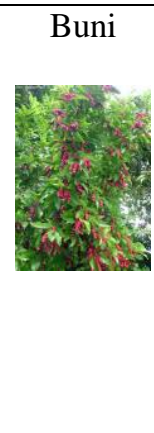 & $\begin{array}{l}\text { Termasuk } \\
\text { akar } \\
\text { tunggang, } \\
\text { putih } \\
\text { kecoklatan. }\end{array}$ & $\begin{array}{l}\text { Bentuk batang } \\
\text { tegak, } \\
\text { berkayu, bulat, } \\
\text { percabangan } \\
\text { simpodial, } \\
\text { hijau keputih- } \\
\text { putihan. } \\
\end{array}$ & $\begin{array}{l}\text { Daun tunggal, } \\
\text { tersebar, } \\
\text { lonjong, } \\
\text { pangkal } \\
\text { runcing, ujung } \\
\text { runcing, } \\
\text { panjang 15-20 } \\
\mathrm{cm} \text {, lebar 5-10 } \\
\mathrm{cm} \text {, pertulangan } \\
\text { menyirip, hijau. }\end{array}$ & $\begin{array}{l}\text { Bunga majemuk, di } \\
\text { ketiak daun, bentuk } \\
\text { tandan, bunga jantan } \\
\text { bertangkai pendek, } \\
\text { kelopak bentuk } \\
\text { cawan, bunga betina } \\
\text { bertangkai, bertaju, } \\
\text { benang sari kuning } \\
\text { kemerahan, tiga } \\
\text { sampai empat, kuning } \\
\text { kemerahan }\end{array}$ & $\begin{array}{l}\text { Buah bulat, saat masih } \\
\text { muda berwarna hijau } \\
\text { setelah masak akan } \\
\text { terlihat merah kehitam- } \\
\text { hitaman, dan berhadap } \\
\text { pada ujung tangkai. Biji } \\
\text { batu, lonjong, putih, } \\
\text { berserat. }\end{array}$ \\
\hline
\end{tabular}

Sumber : Data Primer (2021)

Tabel 7. Morfologi umum dari tumbuhan rambusa yang berpotensi sebagai sumber vitamin $\mathrm{C}$

\begin{tabular}{|c|c|c|c|c|c|}
\hline \multirow{2}{*}{$\begin{array}{l}\text { Nama } \\
\text { tumbuhan }\end{array}$} & \multicolumn{5}{|c|}{ Morfologi tumbuhan } \\
\hline & Akar & Batang & Daun & Bunga & $\begin{array}{l}\text { Buah/ } \\
\text { Biji }\end{array}$ \\
\hline Rambusa & $\begin{array}{l}\text { Akar } \\
\text { serabut, } \\
\text { kuning } \\
\text { kecoklatan. }\end{array}$ & $\begin{array}{l}\text { Batang rambusa } \\
\text { tumbuh menjalar } \\
\text { atau tumbuh } \\
\text { memanjat, } \\
\text { batangnya agak } \\
\text { lunak, } \\
\text { berpenampang } \\
\text { bulat di tumbuhi } \\
\text { rambut-rambut } \\
\text { yang rapat, } \\
\text { panjangnya 1,5-5 } \\
\text { m. duduk daun } \\
\text { tersebar secara } \\
\text { spiral, pada buku- } \\
\text { bukunya terdapat } \\
\text { sulur cabang } \\
\text { pembelit untuk } \\
\text { memanjat. } \\
\text { os }\end{array}$ & $\begin{array}{l}\text { Helai daun } \\
\text { berbentuk hati } \\
\text { dengan tiga } \\
\text { tonjolan } \\
\text { membulat yang } \\
\text { ujungnya runcing, } \\
\text { tonjolan di tengah } \\
\text { lebih besar, } \\
\text { permukaannya } \\
\text { berambut halus } \\
\text { dan rapat, } \\
\text { ukurannya } 4,5- \\
14,5 \text { cm panjang } \\
\text { dan } 3,5-13 \text { cm } \\
\text { lebar, tangkai } \\
\text { daun berambut } \\
\text { halus dan rapat, } \\
\text { panjangnya 2-10 } \\
\text { cm. }\end{array}$ & $\begin{array}{l}\text { Merupakan } \\
\text { bunga tunggal } \\
\text { yang tumbuh } \\
\text { dari ketiak daun, } \\
\text { merupakan } \\
\text { bunga } \\
\text { sempurna, } \\
\text { helaian ganda, } \\
\text { kelopak } \\
\text { lonjong, } \\
\text { berlepasan, } \\
\text { ujung } \\
\text { membulat, } \\
\text { panjang 2-3 cm, } \\
\text { hijauu, benang } \\
\text { sari jumlah } \\
\text { banyak, ungu, } \\
\text { mahkota } \\
\text { berlepasan, } \\
\text { bentuk oval, } \\
\text { ujung } \\
\text { membulat. }\end{array}$ & $\begin{array}{l}\text { Buahnya diselubungi } \\
\text { oleh daun pembalut } \\
\text { yang menyerupai } \\
\text { lumut, berbentuk bulat, } \\
\text { berwarna hijau } \\
\text { bercorak hijau tua dan } \\
\text { merah kuning bila } \\
\text { masak, panjangnya 1,5- } \\
2 \mathrm{~cm} \text { diameter 5-8 cm, } \\
\text { permukaan licin. } \\
\text { Sewaktu buah masak } \\
\text { setelah daun pembalut } \\
\text { lepas. Biji rambusa } \\
\text { memiliki selaput yang } \\
\text { keras. }\end{array}$ \\
\hline
\end{tabular}

Sumber : Data Primer (2021) 
Perbal: Jurnal Pertanian Berkelanjutan

Fakultas Pertanian Universitas Cokroaminoto Palopo

Berdasarkan hasil pengamatan pada yang signifikan yang bisa kita lihat Tabel 2-7 terlihat bahwa morfologi tumbuhan dari karakteristik morfologinya berupa untuk akar, batang, bunga, buah dan biji tidak dataran tinggi dan dataran sedang karakteristik terdapat perbedaan yang signifikan antara daunnya sama yaitu berwarna hijau semua tumbuhan tersebut. Tetapi untuk muda, sedangkan pada dataran rendah morfologi daun terdapat perbedaan karakteristik daunnya yaitu berwarna hijau tua.

Tabel 8. Morfologi bagian-bagian tumbuhan liar yang dimanfaatan, pemanfaatan sebagai minuman, makanan, dan obat, serta bentuk kering/basa di tiga lokasi berbeda.

\begin{tabular}{|c|c|c|c|c|c|c|}
\hline \multirow{2}{*}{$\begin{array}{l}\text { Nama } \\
\text { tumbuhan }\end{array}$} & \multicolumn{2}{|l|}{ Dataran Tinggi } & \multicolumn{2}{|l|}{ Dataran Sedang } & \multicolumn{2}{|l|}{ Dataran Rendah } \\
\hline & PS2MO & $\mathrm{S} / \mathrm{K}$ & PS2MO & $\mathrm{S} / \mathrm{K}$ & PS2MO & $\mathrm{S} / \mathrm{K}$ \\
\hline & $\begin{array}{l}\text { Buahnya langsung } \\
\text { dikonsumsi (masak) }\end{array}$ & S & $\begin{array}{l}\text { Buahnya langsung dikonsumsi } \\
\text { (masak) dan daun mudahnya } \\
\text { bisa langsung dijadikan sayur }\end{array}$ & $\mathrm{S}$ & Obat muntah & $\mathrm{K}$ \\
\hline & $\begin{array}{l}\text { Daunnya dipakai } \\
\text { untuk mengobati } \\
\text { penyakit cacar. }\end{array}$ & S & $\begin{array}{l}\text { Buahnya sangat digemari oleh } \\
\text { anak-anak dan batang daun } \\
\text { dikeringkan kemudian dijadikan } \\
\text { sebagai obat-obatan. }\end{array}$ & S & $\begin{array}{l}\text { Obat untuk } \\
\text { menurunkan } \\
\text { tekanan }\end{array}$ & $\mathrm{S}$ \\
\hline & $\begin{array}{l}\text { Buahnya dijadikan } \\
\text { asam untuk masak } \\
\text { ikan }\end{array}$ & $\mathrm{S}$ & $\begin{array}{l}\text { Buahnya dijadikan asam untuk } \\
\text { masak ikan }\end{array}$ & $\mathrm{S}$ & $\begin{array}{l}\text { Buahnya } \\
\text { dijadikan asam } \\
\text { untuk masak ikan }\end{array}$ & $\mathrm{S}$ \\
\hline Dengen & $\begin{array}{l}\text { Buahnya langsung } \\
\text { dikonsumsi }\end{array}$ & S & $\begin{array}{l}\text { Bahan makanan bagi wanita } \\
\text { saat hamil muda }\end{array}$ & S & $\begin{array}{l}\text { Buahnya } \\
\text { dijadikan asam } \\
\text { untuk masak ikan }\end{array}$ & $\mathrm{S}$ \\
\hline Buni & $\begin{array}{l}\text { Buahnya langsung } \\
\text { dikonsumsi }\end{array}$ & S & Buahnya langsung dikonsumsi & $S$ & $\begin{array}{l}\text { Buahnya langsung } \\
\text { dikonsumsi }\end{array}$ & $\mathrm{S}$ \\
\hline Rambusa & $\begin{array}{l}\text { Buahnya langsung } \\
\text { dikonsumsi }\end{array}$ & $S$ & Buahnya langsung dikonsumsi & S & $\begin{array}{l}\text { Buahnya langsung } \\
\text { dikonsumsi }\end{array}$ & $\mathrm{S}$ \\
\hline
\end{tabular}

Sumber : Data Primer (2021)

Keterangan : PS2MO = Pemanfaatan Sebagai Makanan, Minuman maupun Obat ; $\mathrm{S}=$ Segar $; \mathrm{K}=$ Kering.

Berdasarkan Tabel 8, rata-rata dataran rendah masyarakat memanfaatkan tumbuhan liar dimanfaatkan oleh masyarakat dengan cara mengeringkat senggani terlebih dengan cara mengkomsumsi langsung dalam dahulu untuk kemudian dimanfaatkan sebagai bentuk segar, terkecuali untuk senggani pada bahan tambahan dalam pembuatan obat herbal. 
Tabel 9. Identifikasi daun tumbuhan yang berpotensi sebagai sumber vitamin C

\begin{tabular}{|c|c|c|c|c|c|c|c|c|c|c|c|c|}
\hline \multirow{3}{*}{$\begin{array}{l}\text { Nama } \\
\text { Tumbuhan }\end{array}$} & \multicolumn{4}{|c|}{ Dataran Tinggi } & \multicolumn{4}{|c|}{ Dataran Sedang } & \multicolumn{4}{|c|}{ Dataran Rendah } \\
\hline & \multicolumn{2}{|c|}{$\mathrm{Kd}$} & \multicolumn{2}{|c|}{$\mathrm{Wd}$} & \multicolumn{2}{|c|}{$\mathrm{Kd}$} & \multicolumn{2}{|c|}{$\mathrm{Wd}$} & \multicolumn{2}{|c|}{$\mathrm{Kd}$} & \multicolumn{2}{|c|}{$\mathrm{Wd}$} \\
\hline & Tp & $\mathrm{Tb}$ & $\mathrm{Hm}$ & $\mathrm{Ht}$ & $\mathrm{Tp}$ & $\mathrm{Tb}$ & $\mathrm{Hm}$ & $\mathrm{Ht}$ & Tp & $\mathrm{Tb}$ & $\mathrm{Hm}$ & $\mathrm{Ht}$ \\
\hline Senggani & 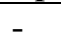 & $\sqrt{ }$ & $\sqrt{ }$ & - & - & $\sqrt{ }$ & $\sqrt{ }$ & - & - & $\sqrt{ }$ & - & $\sqrt{ }$ \\
\hline Ciplukan & - & - & - & - & $\sqrt{ }$ & - & $\sqrt{ }$ & - & $\sqrt{ }$ & - & - & $\sqrt{ }$ \\
\hline Kecombrang & $\sqrt{ }$ & - & $\sqrt{ }$ & - & $\sqrt{ }$ & 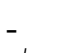 & $\sqrt{ }$ & - & $\sqrt{ }$ & - & - & $\sqrt{ }$ \\
\hline Dengen & - & - & - & - & - & $\sqrt{ }$ & $\sqrt{ }$ & - & - & $\sqrt{ }$ & - & $\sqrt{ }$ \\
\hline Buni & $\sqrt{ }$ & - & $\sqrt{ }$ & 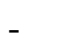 & $\sqrt{ }$ & 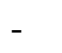 & $\sqrt{ }$ & - & $\sqrt{ }$ & . & - & $\sqrt{ }$ \\
\hline Rambusa & $\sqrt{ }$ & - & $\sqrt{ }$ & - & $\sqrt{ }$ & - & $\sqrt{ }$ & - & - & $\sqrt{ }$ & - & $\sqrt{ }$ \\
\hline
\end{tabular}

Sumber : Data Primer (2021)

Keterangan: $\mathrm{Kd}=$ ketebalan Daun $; \mathrm{Wd}=$ Warna Daun $; \mathrm{Tp}=$ Tipis $; \mathrm{Tb}=$ Tebal $; \mathrm{Hm}=$ Hijau Muda $; \mathrm{dan} \mathrm{Ht}=$ Hijau Tua.

Berdasarkan hasil pengamatan pada tumbuhan berjenis berdaun tipis. Warna pada Tabel 9, pada dataran tinggi ketebalan daun, daun tumbuhan senggani, ciplukan, senggani sangat tebal, sedangkan tumbuhan kecombrang, dengen, buni, dan rambusa juga yang lain seperti kecombrang, buni, dan memiliki jenis warna yang sama yaitu hijau rambusa tergolong jenis berdaun tipis. Untuk muda. Sedangkan di dataran rendah, ketebalan jenis warna daun senggani, kecombrang, daun senggani, dengen, dan rambusa tergolong dengen, buni, dan rambusa memiliki warna jenis tumbuhan bardaun tebal dan tumbuhan yang sama yaitu hijau muda. Pada dataran sedang, ketebalan daun tumbuhan senggani dan tumbuhan dengen memiliki jenis ciplukan, kecombrang, dan buni tergolong jenis berdaun tipis. Pada warna daun tumbuhan senggani, ciplukan, kecombrang, ketebalan yang sama dan untuk ciplukan, dengen, buni, dan rambusa tergolong jenis kecombrang, buni, rambusa adalah jenis tumbuhan bardaun hijau tua.

\section{Ekologi Tumbuhan}

Tabel 10. Kondisi ekologi tumbuhan yang berpotensi sebagai sumber vitamin $C$

\begin{tabular}{|c|c|c|c|c|c|c|c|c|c|c|c|c|}
\hline \multirow{3}{*}{$\begin{array}{l}\text { Nama } \\
\text { Tumbuhan }\end{array}$} & \multirow{2}{*}{\multicolumn{4}{|c|}{$\begin{array}{c}\text { Dataran Tinggi } \\
\text { Ekologi Tumbuhan }\end{array}$}} & \multicolumn{4}{|c|}{ Dataran Sedang } & \multicolumn{4}{|c|}{ Dataran Rendah } \\
\hline & & & & & \multicolumn{4}{|c|}{ Ekologi Tumbuhan } & \multicolumn{4}{|c|}{ Ekologi Tumbuhan } \\
\hline & $\mathrm{Kt}$ & $\mathrm{Tt}$ & Ttb & $\mathrm{pHt}$ & $\mathrm{Kt}$ & $\mathrm{Tt}$ & Ttb & $\mathrm{pHt}$ & $\mathrm{Kt}$ & $\mathrm{Tt}$ & Ttb & $\mathrm{pHt}$ \\
\hline Senggani & $\mathrm{K}$ & Bp & $\mathrm{T}$ & & $\mathrm{K}$ & Bp & $\mathrm{T}$ & & $\mathrm{K}$ & Bp & $\mathrm{T}$ & \\
\hline Ciplukan & - & - & - & & B & $\mathrm{R}$ & $\mathrm{T}$ & & $\mathrm{K}$ & Bp & $\mathrm{T}$ & \\
\hline Kecombrang & $\mathrm{K}$ & Bp & $\mathrm{N}$ & & $\mathrm{K}$ & $\mathrm{Bp}$ & $\mathrm{T}$ & & $\mathrm{K}$ & Bp & $\mathrm{T}$ & \\
\hline Dengen & - & - & - & 7 & $\mathrm{~K}$ & $\mathrm{Li}$ & $\mathrm{T}$ & 6 & $\mathrm{~K}$ & $\mathrm{Li}$ & $\mathrm{T}$ & 4 \\
\hline Buni & $\mathrm{K}$ & $\mathrm{Le}$ & $\mathrm{T}$ & & $\mathrm{K}$ & $\mathrm{R}$ & $\mathrm{T}$ & & K & $\mathrm{Li}$ & $\mathrm{T}$ & \\
\hline Rambusa & $\mathrm{K}$ & Bp & $\mathrm{T}$ & & $\mathrm{K}$ & $\mathrm{Li}$ & $\mathrm{N}$ & & K & Bp & $\mathrm{N}$ & \\
\hline
\end{tabular}

Sumber : Data Primer (2021)

Keterangan : Kt $=$ Kondisi Tanah $; \mathrm{Bp}=$ Berpasir $; \mathrm{Tt}=$ Tekstur Tanah $;$ Le $=$ Lempung $; \mathrm{Ttb}=$ Tempat Tumbuh ; $\mathrm{R}=$ Remah $; \mathrm{pHt}=\mathrm{pH}$ Tanah $; \mathrm{Li}=$ Liat $; \mathrm{K}=$ Kering; $\mathrm{T}=$ Terbuka $; \mathrm{B}=$ Basah $; \mathrm{N}=$ Naungan. 
Perbal: Jurnal Pertanian Berkelanjutan

Fakultas Pertanian Universitas Cokroaminoto Palopo

Berdasarkan hasil pengamatan tempat tumbuh yang sama yaitu terbuka, menunjukkan bahwa pengamatan sedangkan untuk di dataran tinggi tumbuhan ekologi/habitat tumbuhan liar yang ada kecombrang memiliki tempat tumbuh berbeda di setiap dataran. Di dataran tinggi bernaungan. Berdasarkan hasil pengamatan tumbuhan rambusa memiliki tekstur tanah liat dengan menggunakan alat ukur $\mathrm{pH}$ tanah dan memiliki tempat tumbuh terbuka, di bahwa $\mathrm{pH}$ tanah yang berada di dataran tinggi, dataran sedang tumbuhan rambusa memiliki dataran sedang, dan dataran rendah berbeda. tekstur tanah liat dan memiliki tempat tumbuh Di dataran tinggi $\mathrm{pH}$ tanahnya yaitu 7, di naungan, sedangkan di dataran rendah dataran sedang $\mathrm{pH}$ tanahnya 6, sedangkan tumbuhan rambusa memiliki tekstur tanah di dataran rendah $\mathrm{pH}$ tanahnya 4, maka berpasir dan memiliki tempat tumbuh sangat terlihat jelas bahwa tingkat keasaman naungan. Di dataran sedang dan dataran pada setiap tumbuhan liar sangat rendah tumbuhan kecombrang memiliki dipengaruhi oleh tingkat keasaman tanah.

Tabel 11. Pengamatan pada tingkat keasaman/nilai $\mathrm{pH}$ di tiga lokasi berbeda

\begin{tabular}{|c|c|c|c|c|c|c|c|c|c|c|c|c|}
\hline \multirow{3}{*}{$\begin{array}{l}\text { Nama } \\
\text { Tumbuhan }\end{array}$} & \multicolumn{4}{|c|}{ Dataran Tinggi } & \multicolumn{4}{|c|}{ Dataran Sedang } & \multicolumn{4}{|c|}{ Dataran Rendah } \\
\hline & \multicolumn{4}{|c|}{ Tingkat keasaman/nilai pH } & \multicolumn{4}{|c|}{ Tingkat keasaman/nilai pH } & \multicolumn{4}{|c|}{$\begin{array}{c}\text { Tingkat } \\
\text { keasaman/nilai } \mathrm{pH}\end{array}$} \\
\hline & $\mathrm{Bt}$ & $\mathrm{D}$ & $\mathrm{Ba}$ & $\mathrm{Bu}$ & $\mathrm{Bt}$ & $\mathrm{D}$ & $\mathrm{Ba}$ & $\mathrm{Bu}$ & $\mathrm{Bt}$ & $\mathrm{D}$ & $\mathrm{Ba}$ & $\mathrm{Bu}$ \\
\hline Senggani & - & 4 & 4 & 4 & - & 4 & 4 & 4 & - & 3 & 3 & 4 \\
\hline Ciplukan & - & - & - & - & 6 & 5 & - & - & 5 & 5 & - & 4 \\
\hline Kecombrang & - & 4 & - & 4 & - & 4 & - & 4 & - & 4 & - & 3 \\
\hline Dengen & - & - & - & - & - & - & - & 3 & - & - & - & 3 \\
\hline Buni & - & - & - & 4 & - & - & - & 4 & - & - & - & 3 \\
\hline Rambusa & - & - & - & 4 & - & - & - & 4 & - & - & - & 3 \\
\hline
\end{tabular}

Sumber : Data Primer (2021)

Keterangan : $\mathrm{Bt}=$ Batang $; \mathrm{D}=$ Daun $; \mathrm{Ba}=$ Bunga $; \mathrm{Bu}=$ Buah.

Berdasarkan hasil penelitian pada keasaman maka lebih terang pula warna pada Tabel 11, pada parameter tingkat tumbuhan, sedangkan pada dataran tinggi dan keasaman/nilai $\mathrm{pH}$ di tiga lokasi penelitian dataran sedang warna pada tumbuhan liar bahwa tingkat keasaman pada tumbuhan liar tersebut memiliki tingkat keasaman yang yang paling berpotensi yaitu di dataran rendah rendah sehingga mengakibatkan tumbuhan liar karena didukung dengan tingginya tingkat berwarna gelap, dari tingkat keasaman juga 
sangat mempengaruhi warna pada setiap sampel tumbuhan yang dijadikan sebagai bahan penelitian.

\section{PEMBAHASAN}

Tumbuhan liar yang diamati pada penelitian ini, memiliki morfologi tumbuhan yang berbeda pada bentuk, ketebalan dan warna daun. Tumbuhan yang berada pada daratan tinggi dan daratan sedang, memiliki warna daun hijau muda sedangkan pada daratan rendah warna daun pada tumbuhan liar berwarna hijau tua. Perbedaan warna daun tumbuhan liar ini diakabatkan oleh kandungan $\mathrm{pH}$ tanah. Semakin rendah nilai $\mathrm{pH}$, maka semakin tinggi tingkat keasaman tanah, dan semakin tinggi nilai $\mathrm{pH}$ maka semakin rendah kandungan tingkat keasaman tanahnya. Untuk daratan tinggi dan daratan sedang, kandungan $\mathrm{pH}$ yang dimiliki tinggi sedangkan pada daratan rendah kandungan $\mathrm{pH}$-nya rendah. Menurut Handayani dan Karnilawati (2018), menyatakan bahwa reaksi tanah menunjukan sifat kemasaman atau alkalinitas tanah yang dinyatakan dengan nilai $\mathrm{pH}$. Makin rendah nilai angkanya makin tinggi tingkat kemasamannya, dan makin tinggi nilai angkanya makin tinggi nilai alkalinitasnya

Tumbuhan liar yang berpotensi memiliki kandungan vitamin $\mathrm{C}$ berdasarkan hasil penelitian dapat dilihat dari kandungan $\mathrm{pH}$ tumbuhan tersebut. Dari 6 sample tumbuhan liar yang diamati memiliki $\mathrm{pH}$ kisaran 2-6. Menurut Guyton (2007) kadar asam tergantung dari tingkat $\mathrm{pH}$ pada tanaman, dengan tingkat keasaman atau $\mathrm{pH}$ antara 2-4, Semakin besar kandungan asamnya justru semakin rendah nilai pHnya. Ciri-ciri tanaman yang mengandung vitamin $\mathrm{C}$ antara lain daging buahnya berair, secara kimiawi memiliki sifat asam, cenderung memiliki warna cerah seperti kuning, orange, dan hijau cerah.

Tumbuhan liar yang dimanfaatkan masyarakat setempat, contohnya senggani dan ciplukan dimanfaatkan oleh masyarakat sebagai tanaman obat-obatan, sedangkan kecombrang, dengeng, buni, dan rambusa, hanya dimanfaatkannya sebagai bahan makanan, padahal ke-4 tumbuhan tersebut sangat besar potensinya sebagai tanaman obatobatan yang berkhasiat untuk kesehatan dan kebugaran tubuh. Hal ini sesuai dengan pendapat Garjito (2013) bahwa kecombrang memiliki manfaat sebagai obat-obatan yaitu mengobati penyakit kulit seperti campak, menyembuhkan anemia, kurang darah, penambah darah, menguatkan tulang mencegah osteoporosis, dan meningkatkan kinerja otak. Bunne (buni) memiliki manfaat sebagai obat-obatan yaitu kurang darah, darah kotor, hipertensi, jantung berdebar, batuk, Ganguan pencernaan, sifilis, kencing nanah. 
Perbal: Jurnal Pertanian Berkelanjutan

Fakultas Pertanian Universitas Cokroaminoto Palopo

Rambusa memiliki manfaat sebagai mencegah

anemia, menangkal kanker, menjaga kesehatan

tulang, mengatasi gangguan ginjal, mengontrol

tekanan darah, menjaga kesehatan gusi dan

gigi, mengurangi setres, dan mengatasi panas dalam/sariawan.

\section{KESIMPULAN DAN SARAN}

\section{Kesimpulan}

Berdasarkan hasil penelitian yang dilakukan maka disimpulkan bahwa karakter morfologi dan ekologi tumbuhan di dataran rendah cenderung lebih memenuhi syaratsyarat tanaman yang berpotensi sebagai sumber vitamin $\mathrm{C}$ terutama dari warna dan kemasamannya $(\mathrm{pH})$.

\section{Saran}

Disarankan untuk melakukan analisis kandungan asam askorbat pada bagian tumbuhan yang berpotensi sebagai sumber vitamin $\mathrm{C}$ khususnya bagian yang dikonsumsi oleh masyarakat selain itu diperlukan kajian yang lebih banyak lagi tentang potensi-potensi yang dimiliki oleh tumbuhan liar yang banyak terdapat di Kabupaten Luwu.

\section{DAFTAR PUSTAKA}

Crashed. (2009). Metode Penelitian Sosial. Penerbit dan Distribusi. Bandung.

Garjito, M. (2013). Bumbu, Penyedap, dan Penyerta Masakan Indonesia. Gramedia Pustaka Utama. Jakarta.

Guyton, A.C. (2007). Fisiologi Kedokteran. Penerbit dan Distribusi.
Handayani dan Karnilawati. (2018). Karakterisasi dan Klasifikasi Tanah Ultisol di Kecamatan Indrajaya Kabupaten Pidie. Jurnal Ilmiah Pertanian. Vol. 14 No.2. Hal 52-59.

Kesuma dan Bermejo. (2016). Menejemen Keuangan. Erlangga. Jakarta.

Mayasari, D. (2018). Efektivitas Mentimun (Cucumis sativus L.) dan Daun Seledri (Apium graveolens L.) sebagai Terapi Non-Farmokologi pada Hipertensi. Jurnal Majority. 5(5): 119-123.

Pratiwi. (2018). Pencegahan Dini Penyakit TB, Diabetes. Universitas Muhammadiyah Surakarta. Jakarta.

Shafira dan Mailoa. (2018). Meneliti Jalan Menuju Matahari. Sevenbooks. Jakarta. 